\title{
Mediating Effects of Enforcement on Public Procurement Guidelines' Compliance Barriers and Cost Performance of Construction Projects in Nigerian Federal Universities: A Process Macro Approach
}

\author{
*Abdullahi Nafiu Zadawa',2, Abdul Aziz Hussin' and Atasya Osmadi'
}

\begin{abstract}
Published online: 31 August 2018
To cite this article: Abdullahi Nafiu Zadawa, Abdul Aziz Hussin and Atasya Osmadi (2018). Mediating effects of enforcement on public procurement guidelines' compliance barriers and cost performance of construction projects in Nigerian federal universities: A process macro approach. Journal of Construction in Developing Countries, 23(1): 81-102. https://doi. org/10.21315/jcdc2018.23.1.5.
\end{abstract}

To link to this article: https://doi.org/10.21315/jcdc2018.23.1.5

\begin{abstract}
Mediation analysis" is considered as an important research concept in construction research clusters. In this study, we tested the mediation effects' of enforcement as a compliance mechanism on influencing projects' award considered as public procurement guidelines' (PPGs) compliance barriers that affect the cost performance of construction projects. Compliance with PPGs provided within the context of the Public Procurement Act (PPA) 2007 in Nigeria has been a subject of debate. Data for this study was collected from the procurement stakeholders and construction project parties of nine randomly selected Nigerian federal universities using survey questionnaires. They included project clients, contractors registered with the procurement entities, project management consultants and professional consultants selected using the stratified proportionate random sampling method. The data collected was analysed and tested for mediation effects with Process Macro. The results obtained indicated that enforcement as a compliance mechanism has mediated the large negative effects of influencing project award as PPGs' compliance barriers that affects construction project cost performance. Thus, the study concluded that influencing projects award were identified as one of the major PPGs' compliance barriers affecting the cost performance of construction projects in Nigeria. In addition, enforcement was tested and verified as an effective mediator that mitigates the effects of the influencing projects award on construction project cost performance. The study recommends the prompt implementation of enforcement actions in the form of penalties and strict measures against any defaulting stakeholders and construction project parties. Actions to establish the National Council of Public Procurement (NCPP) as provided by the PPA 2007 are also recommended to ensure practicable enforcement actions.
\end{abstract}

Keywords: Procurement guidelines, Enforcement, Cost, Performance, Nigeria

\section{INTRODUCTION}

Construction procurement forms the major business dealings of the construction industry. The construction industry in most developing countries is characterised as a competitive business environment, where priority is given to the lowest possible cost that can give a client good value for money (Oyeyipo et al., 2016; Dulaimi and Shan, 2002). In most developing economies, especially in Nigeria, the majority

'Project Management Department, School of Housing Building and Planning, Universiti Sains Malaysia, 11800, USM Pulau Pinang, MALAYSIA

${ }^{2}$ Quantity Surveying Department, School of Environmental Technology, Abubakar Tafawa Balewa University PMB 0248 Bauchi, NIGERIA

"Corresponding author: nafiuzadawa@gmail.com 
of public construction projects are awarded via a competitive bidding process which necessitates objectivity, equity, openness, accountability and the fair dissemination of information amongst the various stakeholders concerned (Shehu, 2014; Abdullahi, Hussin and Osmadi, 2015; Ademola and Ajibola, 2014). Achieving the stated tendering's basic requirements entails the appropriate abidance with the PPGs.

Issues of influencing construction projects' award have been described by quite a number of authors as one of the major barriers affecting the compliance to PPGs in most developing countries, including Nigeria (Hui et al., 2011; Fayomi, 2013; Jibrin, Ejura and Augustine, 2014; Abdullahi, Hussin and Osmadi, 2015; Shehu, 2014; Migosi et al., 2013). Specifically, in Nigerian federal universities, the awarding of construction projects is usually influenced either from the ministry or at the procurement entity level (Shehu, 2014). According to Fayomi (2013), the most common tactics of influencing construction projects' award both at the procurement entity and ministry levels are through revealing vital bidding information to certain bidders which offers them higher chances of winning by submitting a tender figure if not exact but near to the expected quotation figure. Whilst, in some instances, projects are awarded to the university along with an assigned contractor right from the ministry (Dahiru, 2014). These frequent construction procurement irregularities violate the procurement process regulations thus are regarded as PPG compliance barriers and the majority of the construction procurement professionals and procurement entity's staff engaged in such irregularities are doing so to avoid been sacked or maltreated by the senior procurement officers and/or the directors of the procurement entities (Akech, 2006; Fayomi, 2013; Shehu, 2014).

The unceasing project award influences considered as barriers to PPGs compliance have been affecting the entire decision making process of construction procurement practices and they continue to impact negative consequences on the whole procurement system ethics, moral values of the procurement entities and the honesty and credibility of the procurement stakeholders and construction project parties (Kangogo and Kiptoo, 2013). In a nut shell, all the highlighted issues have resulted from non-compliance with the PPGs amongst the major procurement stakeholders and construction project parties, which affects the performances of construction projects in the long run.

Although most of the developing countries, including Nigeria, have already enacted their respective procurement laws and policies, they are facing similar defiance of compliance with the policies. For instance, in Malaysia, a study conducted by Hui et al. (2011) revealed that, project award influences from external parties and nepotism of different kinds were amongst the major complaints made by the contractors interviewed. These have been affecting the procurement bidding phase and of course, the entire construction procurement performance. In South Africa, the intrusion and egocentric act of senior public office holders whilst discharging public services was observed to have weakened their motivation to remain honest, especially in terms of construction project awards (Pillay, 2004). In Sri Lanka, Raymond (2008) opined that public procurement has been a source of personal gain to top public officials, especially ministers and political office holders. Eventually, this has been the foremost constraint to compliance with PPGs. In Africa, countries that have recently passed into law their respective procurement policies, such as Ghana, Kenya, Uganda and Nigeria, such policies are merely considered by the procurement stakeholders and project parties as lengthy and tedious protocols thus affecting their compliance and subsequent outcome on the 
projects executed (Ameyaw, Mensah and Osei-Tutu, 2011; Eyaa and Oluka, 2011; Onyinkwa, 2013; Migosi et al., 2013).

Although previous studies have highlighted PPGs' non-compliance issues that affect construction procurement processes generally, they are delimited to the provision of insight into the construction project delivery and related aspects. The PPGs' compliance barriers that affect the cost performance of construction projects and the hypothesised significant impact of enforcement as a compliance mechanism were not considered by the prior studies. Identifying PPGs' compliance barriers and assessing the mediation effects of enforcement on the latter, which positively affects construction project cost performance, is a bold step towards improving construction products, cost-wise.

Influencing projects award considered as a barrier to compliance with PPGs refers to the main independent variable (IV) of the study that affects construction project cost performances as the dependent variable (DV) through the enforcement mechanism as the mediating variable of the study (MV). The factors contributing to influencing project awards are items that have a direct proportional cost relationship with the construction project performance (Abdullahi, Hussin and Osmadi, 2015). The factors causing influences in project awards are compliance-related factors that lead to non-compliance with the PPGs and, subsequently, to poor workmanship followed by re-work and the poor cost performance of the project in the long run. These include two major dimensions which are internal influences and external influences. Project awards are influenced internally by altering the transparency of the bidding process via leaking vital information to a favoured bidder, violating the ethical bidding process and ignoring the obvious shortcomings of some tenderers from amongst others (Fayomi, 2013; Abdullahi, Hussin and Osmadi, 2015; Kangogo and Kiptoo, 2013). On the other hand, project awards are sometimes influenced through external intrusion, especially by the directors at the ministry and public organisational level who are not within the procurement entity domain (Hui et al., 2011; Akech, 2006; Jibrin, Ejura and Augustine, 2014; Ademola and Ajibola, 2014).

Cost performance refers to the main outcome variable, the DV of the study, the cost performances of a construction project require ample inputs and commitment from all the procurement stakeholders and project parties concerned at all stages of the construction procurement process. For the project to operate efficiently and effectively, the prerequisite PGs need to be appropriately followed. Unfortunately, the award of construction projects in most procurement entities in Nigerian federal universities are influence-based due to the non-compliance to the PPGs thus affecting the overall performance of the projects, especially the cost performance (Shehu, 2014; Williams-Elegbe, 2009; Jibrin, Ejura and Augustine, 2014).

Enforcement of PPGs was proposed as a MV in this study, with the primary target of mediating the effects of influencing project awards (IV) on construction project cost performances (DV). Enforcement is an action by the regulatory bodies here referred to as procurement entities to ensure full compliance with the required rules. Prior studies have reported the great impacts of enforcement as a strong compliance mechanism that improves the compliance with regulations in some of the other economic sectors (Tukamuhabwa, 2012; Zubcic and Sims, 2011 ; Imperato, 2005).

Accordingly, the poor cost performance of a construction project as a result of non-compliance with the PPGs has grown to be an undying fact, posing a challenge to the construction industry that is yet to be resolved, especially in developing countries. In Nigeria, reasons owing to this include the disreputable 
practices of influencing project awards both at the procurement entity level as well as at the ministry and organisational levels.

This study is aimed at:

1. Identifying the major public procurement guidelines' (PPGs) compliance barriers that affect the cost performance of construction projects.

2. Assessing the relationship between the PPGs' compliance barriers and the cost performance of construction projects.

3. Examining the mediating effects of enforcement as a compliance mechanism between the PPGs' compliance barriers and the cost performance of the construction projects.

\section{INFLUENCING PROJECT AWARDS AS A PPGS' COMPLIANCE BARRIER (INDEPENDENT VARIABLE)}

Influencing project awards is a predominant deceptive role in the bidding and procurement process considered as a barrier to effective compliance with PPGs which affects construction project cost performance. According to Jacob (2010), project awards are influenced both at the procurement entity and at the ministry or public organisational levels and all sorts of nepotism in project awards are one of the most challenging barriers for the compliance with procurement guidelines in Nigeria (Fayomi, 2013; Shehu, 2014).

In Nigerian federal universities, the tendering and bidding process for construction project awards is unrelentingly affected by influences from both within and outside the procurement entities (Shehu, 2014; Jacob, 2010; Fayomi, 2013). It is affirmed that procurement entities usually pre-arrange with their favoured prospective contractors prior to making the first move of the procurement process (Abdullahi, Hussin and Osmadi, 2015; Shehu, 2014). Project award influences may perhaps be internally initiated at the procurement entity usually by the directors in collaboration with in-house senior construction procurement professionals (Akech, 2006; Fayomi, 2013). Whilst external project award influences might emanate directly from external bodies commonly prompted by directors, ministers and high political office holders (Ademola and Ajibola, 2014; Jibrin, Ejura and Augustine, 2014), famous business folks and eminent statesmen in view of the persuasive influence they have in society, especially in developing countries (Hui et al., 2011) and in some rare cases, the board of directors of public organisations and institutions (Jibrin, Ejura and Augustine, 2014). These deceptive acts have been altering the transparency of the public procurement process, which is regarded as the PPGs' nonconformity actions contributing to the continuing problem of cost overrun in the construction industry that is yet to be tackled; for it is obvious that, the final contract sum of such influence-based project tends to be irrationally high (Jibrin, Ejura and Augustine, 2014). Past studies attributed the rampant cases of project award influences in Nigeria to the refusal of the federal government to establish the National Council of Public Procurement (NCPP) as provided in the content of PPA 2007 (Jibrin, Ejura and Augustine, 2014; Williams-Elegbe, 2011; Shehu, 2014). 


\section{COST PERFORMANCE OF CONSTRUCTION PROJECTS (DEPENDENT VARIABLE)}

Cost performance of a construction project is affected by the barriers to compliance with PPGs, especially project award influences. The performance of a construction project, cost-wise, designates the fulfilment of major project performance criteria (Gambo, Said and Ismail, 2016). High cost perfromance is achieved when the project is executed in accordance with the specifications and regulatory manual, such as PPGs: therefore, non-compliance to the specifications, conditions of the contract and procurement guidelines affect the cost performance of the construction projects (Abdullahi, Hussin and Osmadi, 2015).

The delivery of a construction project is termed successful when the project is completed within the targeted cost, time estimated and specified quality (Gambo, Said and Ismail, 2016). Thus, cost remains one of the key determinant factors of measuring the performance of a construction project (Akinsiku and lyagba, 2014; Cooke-Davies, 2002; Koelmans, 2004). Cost has a significance input that affects the entire project life cycle and project performance can only be ascertained after a project is successfully and practically completed within the appropriate cost limit (Azhar, Farooqui and Ahmed, 2008; Othman et al., 2010). In construction project delivery, performance is generally established in relation to the extent of compliance with the procurement procedural guidelines as provided by the procurement rules and polices ( $\mathrm{Ng}$, Palaneeswaran and Kumaraswamy, 2002). Therefore, a project executed in accordance with the specifications, procedural guidelines, budget cost and time limit is said to have satisfied the basic performance requirements; thus, it has fulfilled the client's need of good value for money (Frimpong, Oluwoye and Crawford, 2003; Low and Quek, 2006). Projects that are not executed based on the procurement guidelines as specified by the procurement policies and conditions of the contract can lead to rework and later variations which affects the cost performance of the project negatively. For improved cost performance, all significant barriers to compliance with the procurement guidelines should be identified and assessed in order to improve construction project cost performances.

\section{ENFORCEMENT AS A COMPLIANCE MECHANISM (MEDIATING VARIABLE)}

Enforcement was identified as a strong mechanism that improved compliance in all sectors of the economy: thus, it has been introduced into the current study as the mediating variable. Enforcement as an abidance mechanism is referred to as the necessary action taken by regulatory bodies and procurement entities to ensure compliance with the PPGs (Zubcic and Sims, 2011). The enforcement mechanism in the form of applications, prosecutions and penalties to defaulters was found to have a great supremacy that improves compliance with rules, generally (Tukamuhabwa, 2012; Zubcic and Sims, 2011). To be specific, developing countries, such as Nigeria, Bangladesh, India, Sri Lanka and Venezuela, were observed to be affected more by irregularities in the public procurement processes due to the non-enforcement of the appropriate procurement policies (Raymond, 2008; Tukamuhabwa, 2012). Okeahalam (2004) maintained that amongst the developing countries, especial in Africa, Nigeria and Ghana, are characterised with weaknesses in terms of law enforcement generally. Achieving a great level if not full compliance to the PPGs requires a threat of legal sanctions which can be attained by enforcement actions (Tukamuhabwa, 2012). This is because, enforcement actions send a strong 
consciousness signal to firms, individuals and professionals as well as the entirety of the stakeholders and project parties concerned that violators will be prosecuted. Enforcement as a threat naturally implants a culture of abidance thus, it has ever since been considered as a fundamental element in any compliance regime (Gunningham and Kagan, 2005; Sutinen and Kuperan, 1999). This study proposed and tested enforcement as a mediator to enhance compliance with the PPGs by mitigating the effects of influencing project awards on the cost performance of construction projects.

\section{HYPOTHETICAL MEDIATION MODEL OF THE STUDY}

Figure 1 presents the hypothetical mediation model of this study which is an adoption of Model 4 for process macro developed by Hayes (2013[b]). The model has a single mediating variable (Enfrcmnt) positioned between the independent variable (Inflcng) and the outcome variable (CsttPerf). Figure 1(a) shows the total effect model (c-path) between IV and DV, whilst Figure 1 (b) presents the indirect effects model along the indirect paths (a-path and b-path) and the direct effects between IV and DV whilst controlling MV (c'-path).

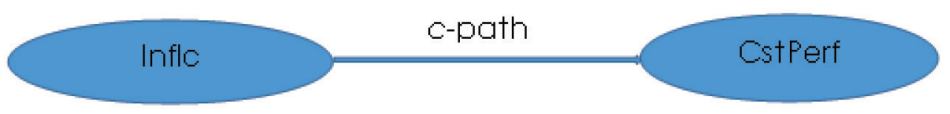

Figure 1 (a). Direct Effects Model

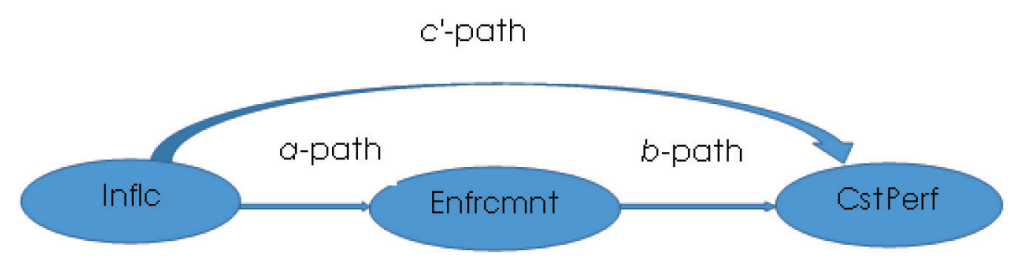

Figure $1(b)$. Indirect Effects Model

Figure 1. Hypothetical Mediation Model of the Study

Based on the hypothetical model of the study (Figure 1), IV = Infllc, MV = Enfrcmnt and DV = CstPerf:

Mathematically total effect $=$ Direct effects + Indirect effects

$c=c^{\prime}+a b$ 
The total effect of IV on DV is the regression coefficient predicting DV from IV in the model detonated as (c-path) presented in Figure 1(a). Whilst Figure 1 (b) shows the indirect effects of IV on DV which is the product of the a-path and b-path $(a b)$. Whereas, the a-path is the regression coefficient estimating the Mediating variable MV from IV and the b-path in the model is the partial regression weight for the mediating variable MV estimating DV from both IV and MV. Also, the c'-path is shown in Figure 1b, which is the direct effect of IV on DV whilst controlling MV.

\section{THEORETICAL CONCEPT OF THE STUDY}

This study has been guided by two main theories: namely, the principal agent theory and the institutional theory used in framing the hypothesised model of the study in accordance with the research questions, objectives and methodology. These theories have been adopted from prior similar studies on issues of compliance with public procurement regulations, such as the studies of Eyaa and Oluku (2011), Onchweri and Mutari (2015), Sang and Mugambi (2014) and Tukamuhabwa (2012).

According to the concept of the principal-agent theory, when there are discrepancies between regulatory policies, for example the PPGs and the formal procedure or public system, then there is a likelihood of non-compliance to the guidelines or the regulatory policies guiding the system (Reimarova, 2011). In addition, Bolton and Dewatripont (2005) maintained that the principle-agent theory is generally considered as the contract theory that involves different sets of family models used in assessing and evaluating public procurements and related contract processes.

Whilst the institutional theory describes the extent of the compliance with the regulatory guidelines, rules, norms, routines and procedural manual within an organisation or system (Scott, 2005), it is a commonly used theory in assessing public procurement elements (Luhmann, 2010). Institutions constitute three basic pillars: regulatory, normative and cultural cognitive (Scott, 2005). The regulatory pillar stresses some basic compliance mechanism, such as guidelines, procedural manual and enforcement (expedience as the basis of compliance). The normative pillar for compliance is based on norms, values and social responsibilities. Whilst, the cultural-cognitive pillar encompasses understanding, beliefs, symbols and identity (Scott, 2005; Tukamuhabwa, 2012).

Based on the concept of the Principal-Agent and Institutional theories that guided and underpinned the study model, it can be understood that construction procurement activities in procurement entities of Nigerian federal universities and other public tertiary institutions in the country are guided by the public procurement guidelines as provided by the PPA 2007. Consequently, the concept of the principalagent theory and the three pillars of the institutional theory, i.e., regulatory, normative and cognitive, highlighted enforcement as a compliance mechanism as profound by Scott (2005) and Reimarova (2011). 


\section{RESEARCH METHODOLOGY}

The study method was designed as quantitative and a structured survey questionnaire was administered to 540 construction procurement stakeholders and project parties in the procurement entities of Nigerian federal universities. The study focused on the northern region of Nigeria with 22 federal universities out of the 40 federal universities in the country. The region covers $80 \%$ of the country's land mass, with three geopolitical zones, 19 states and Abuja as the federal capital territory (Commision, 2000; Gambo, Said and Ismail, 2014).

The study population involved a total of 1,870 construction project parties and procurement stakeholders, mainly project clients, registered contractors, registered project managers and registered professional consultants. The stratified proportionate random sampling method was adopted in selecting samples for this study as it assures a certain level of precision (Delenius and Hodges, 1959). Each category of the various stakeholders, as listed, was considered as a strata and the stratified proportionate sample from each strata was calculated to make up the research sample of the current study using the formula below:

Stratified proportionate sample of each strata $N_{1}=\left(X_{n} \times Y_{n}\right) \div N$

where,

$X_{n}=$ Strata population

$Y_{n}=$ Strata sample

$N=$ Total population

The summation of the individual sample from each strata $\left(N_{1}+N_{2}+N_{3}+N_{4} \ldots\right)$ gave the total sample required.

Table 1 shows the respective population of each strata and the estimated stratified proportionate random sample of each starter.

Table 1. Study Population and Selected Samples

\begin{tabular}{lcc}
\hline \multicolumn{1}{c}{ Stakeholders } & Population of Each Strata & Strata Sample $\left(X_{n} \times Y_{n}\right) \div \mathbf{N}$ \\
\hline Registered contractors & 1,032 & 177 \\
Project client & 426 & 73 \\
Professional consultants & 280 & 48 \\
Project managers & 132 & 24 \\
Total & 1,870 & 320 \\
\hline
\end{tabular}




\section{Assessing the Mediation Effects of Enforcement for Compliance with PPGs that Affects Cost Performance}

Process Macro version 2.15 was used in assessing the mediation effects on the study model as hypothesised (Figure 1), the direct and indirect effects of the mediating variable (Enfrcmnt) were assessed through two distinct tests initiated by Baron and Kenny (1986) and Sobel (1986), respectively:

1. Bootstrap confidence interval approach.

2. Sobel Test method.

\section{Measurement Scale Used in Assessing the Study Variables}

All the three constructs of the study: Inflc, Enfrcmnt and CstPerf, were measured using a five-point Likert scale. The Likert scale is an efficient, uni-dimensional scale of measurement that makes sure all items measure the same thing (Cornalba and Giudici, 2004). The scale was used in measuring the study's constructs based on the survey instrument as it describes the extent of agreement or otherwise of the measurement items. As it is on the study instrument, the scale ranges from 1 which denotes "Strongly disagree" to 5 that denotes "Strongly agree". The measurement scale for the construction project cost performance as the dependent construct of the study was adopted from Gambo, Said and Ismail (2016). The scale used in measuring the mediating effects of enfocement on the influencing projects award that affects cost perfomance was adopted from the studies of Sang and Mugambi (2014).

\section{Data Collection}

A total of 379 useable, out of the 410 retrieved questionnaires were analysed, 31 were rejected due to a lack of clarity, differences in the responses and a few copies that were totally unanswered. These yielded $70 \%$ and $76 \%$ response and return rates, respectively, which was considered reasonably above the researches of Ojo and Gbadebo (2014) and Eyaa and Oluka (2011), with response rates of $47 \%$ and $50 \%$, respectively. The data was analysed using Process Macro written by Hayes (2012). Process macro is as an add-on in the SPSS for mediation analysis as well as computing and analysing direct and indirect effects in research model (Hayes and Preacher, 2014). 
Abdullahi Nafiu Zadawa, Abdul Aziz Hussin and Atasya Osmadi

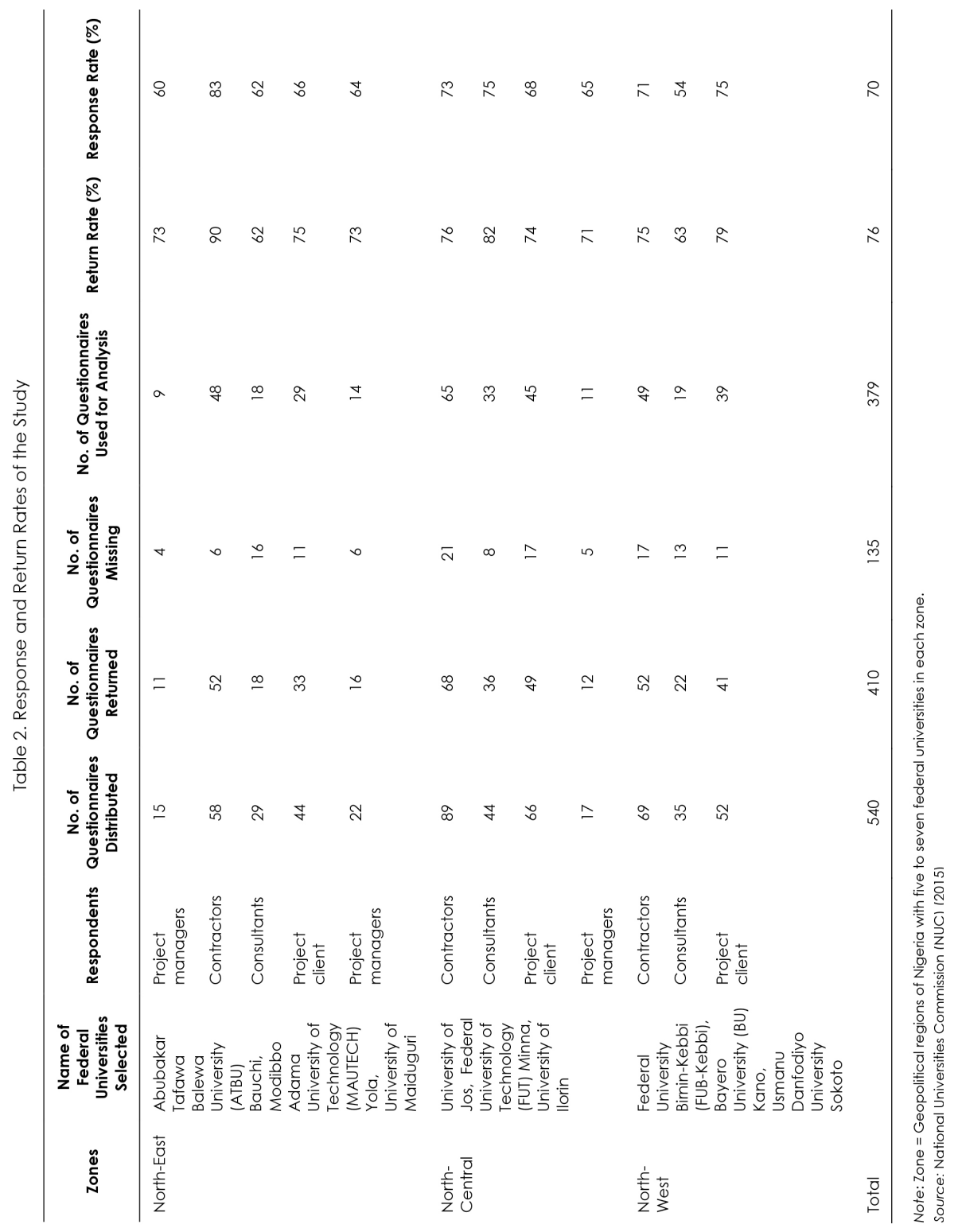




\section{Data Analysis and Results Presentation}

Process Macro version 2.15 written by Hayes (2012) was used in analysing the collected data. The data were bootstrapped to 1,000 times with replacement. The details of the result findings is presented as follows.

\section{Total relationship effects between Inflc and CstPerf (c-path)}

Table 3 presents process macro output for the total effects of Inflc (the study IV) on CstPerf (DV of the study). The result shows a significant effect along the c-path (0.2841), $p$-value $=0.0000$ significant at the $p<0.05$ level of significance, a test of the statistical significance, + (18.2092); whilst, the lower limit confidence interval (LLCI) and upper limit confidence interval (ULCI) were 0.2535 and 0.3148 , respectively. Having no zero between the lower and upper level bootstrapped confidence intervals ( $\mathrm{LLCl}$ and $\mathrm{ULCl}$ ) in addition to the $\mathrm{p}$ and $t$ values obtained, it can be established that the total effects of IV on DV (c-path) was significant (Baron and Kenny, 1986; Hayes, 2013[a]).

Table 3. Process Macro Output for the Effects of Relationship along the c-Path (Total Effects)

\begin{tabular}{|c|c|c|c|c|c|c|}
\hline \multicolumn{7}{|c|}{ Outcome: CstPerf } \\
\hline \multicolumn{7}{|c|}{ Model Summary } \\
\hline$R$ & $R$-sq & MSE & $\mathrm{F}$ & df 1 & df2 & $p$ \\
\hline 0.6865 & 0.4713 & 0.0600 & 331.5760 & 1.0000 & 372.0000 & 0.0000 \\
\hline \multicolumn{7}{|l|}{ Model } \\
\hline & coeff & SE & $T$ & p & $\mathrm{LLCl}$ & $\mathrm{ULCl}$ \\
\hline Constant & 1.1884 & 0.0944 & 12.5891 & 0.0000 & 1.0027 & 1.3740 \\
\hline Inflc & 0.2841 & 0.0156 & 18.2092 & 0.0000 & 0.2535 & 0.3148 \\
\hline \multicolumn{7}{|c|}{ Covariance matrix of regression parameter estimates } \\
\hline & & & Constant & & Inflc & \\
\hline Constant & & & 0.0089 & & -0.0015 & \\
\hline Inflc & & & -0.0015 & & 0.0002 & \\
\hline
\end{tabular}

\section{Indirect Relationship Effects between Inflc and Enfrcmnt (a-path)}

Table 4 below presents the process macro output for the first indirect effects of Inflc (the study IV) on Enfrcmnt (the MV of the study), as indicated the coefficient of the first indirect effects along the a-path (0.4305) and a test of the statistical significance, $t=44.2069$ and $p=0.0000$ (significant) with the $p<0.05$ level of significance. Whilst, the LLCl and ULCl obtained along this path were 0.2387 and 0.4703, respectively. Thus, the a-path having showed a positive effect based on the coefficient of determination obtained, $p$ and $t$ values obtained, was significant (Baron and Kenny, 1986; Hayes, 2013[a]). Therefore, the effects of the relationship 
between influencing project (IV) and enforcement (MV) was statistically significant based on the model outcome.

Table 4. Process Macro Output Showing Effects of the Relationship along the a-Path (Indirect Effect)

\begin{tabular}{|c|c|c|c|c|c|c|}
\hline \multicolumn{7}{|c|}{ Outcome: Enfrcmnt } \\
\hline \multicolumn{7}{|c|}{ Model Summary } \\
\hline$R$ & $R$-sq & MSE & $\mathrm{F}$ & df 1 & df2 & $p$ \\
\hline 0.9166 & 0.8401 & 0.0233 & 1954.2505 & 1.0000 & 372.0000 & 0.0000 \\
\hline \multicolumn{7}{|l|}{ Model } \\
\hline & coeff & SE & $t$ & p & $\mathrm{LLCl}$ & $\mathrm{ULCl}$ \\
\hline Constant & 0.3545 & 0.0589 & 6.0177 & 0.0000 & 0.2387 & 0.4703 \\
\hline Inflc & 0.4305 & 0.0097 & 44.2069 & 0.0000 & 0.4113 & 0.4496 \\
\hline \multicolumn{7}{|c|}{ Covariance matrix of regression parameter estimates } \\
\hline & & & Constant & & Inflc & \\
\hline & Constant & & 0.0035 & & -.0006 & \\
\hline & Inflc & & -0.0006 & & 0.0001 & \\
\hline
\end{tabular}

\section{Indirect Effects of the Relationship between Enfrcmnt and CstPerf (b-path)}

Mediation result for this part of the model with CstPerf as the outcome variable and both Enfrcmnt and Inflc as predictors are presented in Table 5 below. The coefficient of determination for b-path was (1.1196), $p=0.0000$ (significance) at $p<0.05$ level of significance and the, test of statistical significance, $t=18.8103$ whilst $\mathrm{LLCl}$ and ULCI were 1.0026 and 1.2366, respectively. Thus, the b-path also showed a significant indirect effect between the linked variables, thus the path has fulfilled the condition of mediation occurrence (Baron and Kenny, 1986; Hayes, 2013[b]).

\section{Direct Effects of the Relationship between Inflc and CstPerf Whilst Controlling Enfrcmnt (c'-Path)}

Subsequently, the second path of the model equally provided coefficient of determination for the c'-path $(-0.1978), p=0.0000$ ( $p<0.05), \mathrm{LLCl}$ and ULCl at -0.2528 and -0.1429 , respectively and the test of the statistical significance at $\dagger=$ -7.0764 as presented in Table 5. This portion of the model portrayed an insignificant relationship along the $C^{\prime}$-path, fulfilling the fourth requirement of the mediation occurrence, accordingly (Baron and Kenny, 1986). Since there was a zero value between $\mathrm{LLCl}$ and $\mathrm{ULCl}$, based on a $95 \%$ selected confidence, mediation has occurred in the model (Hayes, 2012). Therefore, enforcement should mediate the effects of influencing projects award on cost performance of construction projects. 
Table 5. Process Macro Output for the Effects of the Relationship along b-Path and C'-Path

\begin{tabular}{lcccccc}
\hline \multicolumn{7}{c}{ Outcome: CstPerf } \\
\hline$R$ & $R$-sq & MSE & $F$ & Df1 & Df2 & $P$ \\
0.8540 & 0.7294 & 0.0308 & 499.9437 & 2.0000 & 371.0000 & 0.0000 \\
Main model & & & & & \\
& Coeff & SE & $T$ & $P$ & LLCl & ULCl \\
Constant & 0.7915 & 0.0708 & 11.1727 & 0.0000 & 0.6522 & 0.9308 \\
Enfrcmnt & 1.1196 & 0.0595 & 18.8103 & 0.0000 & 1.0026 & 1.2366 \\
Inflc & -0.1978 & 0.0280 & -7.0764 & 0.0000 & -0.2528 & -0.1429 \\
Covariance matrix of regression parameter estimates & & & \\
& & Constant & Enfrcmnt & InflC & & \\
& Constant & 0.0050 & -0.0013 & -0.0002 & & \\
& Enfrcmnt & -0.0013 & 0.0035 & -0.0015 & & \\
& Inflc & -0.0002 & -0.0015 & 0.0008 & & \\
\hline
\end{tabular}

According to Hayes (2012), computing the total effects prior to estimating the indirect effects is not necessary in the modern concept of mediation analysis, accordingly this study has also focused mainly on the mediation effects which are the indirect effect paths in the model (a-path and b-path). The indirect effects in the mediation model were computed as the difference between the total effects (c-path) and direct effects (c'-path), i.e. $c-c^{\prime}(0.2841-[-0.1978])=0.4819$ (Hayes, 2012). Alternatively, the indirect effect was computed as the product of the a-path and $b$-path, $(0.4305 * 1.1196)=0.4819$ (Hayes, 2013[b]). Additionally, since $c^{\prime}<c$, this depicted the indirect effects of Inflc (IV) on CstPerf (DV) through the Enfrcmnt (MV) as recommended by Baron and Kenny (1986).

From the process macro output as presented in the final mediation model of the study (Figure 2), indeed, $c=c^{\prime}+a b: 0.2841=(-0.1978)+0.4819$. Therefore, the direct effect ( $c^{\prime}$-path $=-0.1978$ ) was not statistically different than zero (at a $p<0.05$ level of significance); but, the indirect effect was statistically different than zero $(0.4819)$, signifying the prediction that enforcement (the mediating variable) as a compliance mechanism will possibly mediate the effects of the projects award Influencing (independent variable) on construction project cost performance (dependent variable) of the study.

Moreover, modern mediation inferences are now based on the explicit quantification of the indirect effects only. In addition the statistical test observed the non-normality of the indirect effect sampling distribution instead of the statistical significance along the indirect paths, i.e. a-path and b-path (Hayes, 2012). The symmetric bootstrap confidence interval $(\mathrm{Cl})$ is the most widely used approach in achieving that. As seen in Table 6, the indirect effect $(0.4820)$ was positive and statistically different from zero supported by a $95 \%$ bias-corrected bootstrap confidence interval levels that did not include zero (0.4207-0.5433). It can be said that this $\mathrm{Cl}$ is quite symmetric around the calculated value of 0.4819 , which is the 
indirect effect of Enfrcment (mediating variable) between Inflc (independent variable) on CstPerf (dependent variable).

Table 6. Summary of the Total, Direct and Indirect Effects of the Study Model

\begin{tabular}{llllll}
\hline \multicolumn{5}{c}{ Total, Direct and Indirect Effects } \\
\hline \multicolumn{5}{c}{ Total Effect of X on Y } \\
\hline Effect & SE & $T$ & $p$ & LLCl & ULCl \\
0.2841 & 0.0156 & 18.2092 & 0.0000 & 0.2535 & 0.3148 \\
Direct effect of X on Y & & & & \\
Effect & SE & $T$ & $p$ & LLCl & ULCl \\
-0.1978 & 0.0280 & -7.0764 & 0.0000 & -0.2528 & -0.1429 \\
Indirect effect of X on Y & & & & \\
Effect & & Boot SE & LLCl & ULCl & \\
0.4820 & & 0.0311 & 0.4207 & 0.5433 & \\
\hline
\end{tabular}

The study result based on the bootstrap confidence interval as presented above was further supported and re-confirmed by the Sobel test output in Table 7, which was also generated simultaneously with bootstrapped $\mathrm{Cl}$ results by the Process Macro (Hayes, 2013[a]; MacKinnon, Lockwood and Williams, 2004). The Sobel test is based on the product of the coefficient by estimating the standard error of the a-path and b-path based on the assumption that the product of (ab) is normally distributed (Hayes, 2012).

\section{Macro process Sobel test mediation result}

As shown in Table 7 below, the normal theory test (Sobel test) for the indirect effect was 0.4820 , which indicated that the value was different from zero; re-confirming the occurrences of the mediation in the study model with $Z=17.3048$ and the $p$-value $=0.000$ significance at a $p<0.05$ level of significance (Hayes, 2012).

Sobel Test (Normal Theory test) $=Z$ score test if $c-c^{\prime} \neq 0$

Table 7. Sobel Test Validation Mediation Result for the Study Model

\begin{tabular}{|c|c|c|c|c|}
\hline \multicolumn{5}{|c|}{ Preacher and Kelley (2011) Kappa-Squared } \\
\hline & Effect & Boot SE & Boot LLCI & Boot ULCI \\
\hline Enfrcmnt & 0.6572 & 0.0273 & 0.6008 & 0.7092 \\
\hline \multicolumn{5}{|c|}{ Normal theory test for indirect effects } \\
\hline Effect & SE & \multicolumn{2}{|c|}{ z } & $P$ \\
\hline . 4820 & .0279 & \multicolumn{2}{|c|}{17.3048} & 0.0000 \\
\hline
\end{tabular}




\section{FINAL MEDIATION MODEL OF THE STUDY}

The process macro mediation outcome based on the hypothesised model provided the four different coefficients along the various paths that make up the main study final or established mediation model as shown in Figure 2 below.

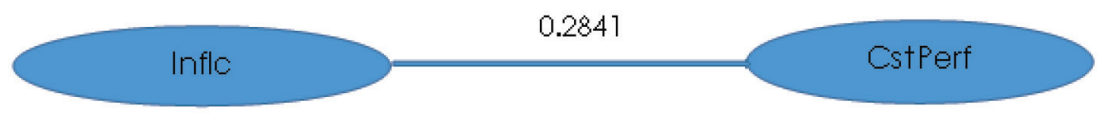

Figure 2(a). Direct Effects Model

$-0.1978$

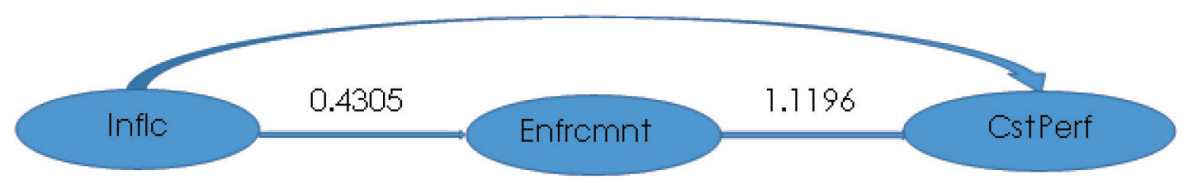

Figure 2(b). Indirect Effects Model

Figure 2. Final Mediation Model of the Study

\section{DISCUSSION OF THE RESULTS}

The main objective of this study has been to analyse the mediating effects of the enforcement of PPGs' compliance as an efficient compliance instrument on influencing project awards as it affects the cost performance of construction projects. Process Macro as a versatile statistical mediation tool was used in achieving the study objectives. Influencing project awards was identified through an extensive literature review as one of the major barrier that affects full compliance with PPGs amongst major construction procurement stakeholders and project parties. Existing literature shows that influencing project awards originates both within the procurement entities known as internal project award influencing and, as well, from external bodies, usually ministries and other governmental organisations (Fayomi, 2013; Hui et al., 2011; Shehu, 2014; Abdullahi, Hussin and Osmadi, 2015). These supported the earlier predictions based on the study's hypothetical model. The measurement of the model shows that the total effect (c-path) of the model was significant which means that the project award influences affects the cost performance of construction projects in Nigeria.

The model path coefficients between Inflc and Enfrcmnt (a-path) were significant. Similarly, Enfrcmnt affects CstPerf, significantly (b-path). The result of the direct effects in the model between Inflc and CstPerf whilst controlling Enfrcmnt (c'-path) was non-significant. From the study's findings, the model has fulfilled all the basic conditions required for mediation effects to occur as recommended by Baron and Kenny (1986) and Hayes (2013[b]). Table 8 presents the summary of the study results for all the four paths that make up the study model: 
1. Firstly, influencing project awards affects the cost performance of construction projects. This is probably due to the lack of competition in project awards as the projects are usually awarded based on influences and on unrealistic contract sums, cancellation of bidding by the procurement entities to pave way for influencing project awards without valid reasons and rework caused poor workmanship of incompetent contractors awarded based on influences. Accordingly, the study's result shows that both external and internal project award influences are barriers to compliance with public procurement guidelines in the procurement entities of federal universities in Nigeria. These identified barriers of compliance to PPGs were observed with negative effects on the cost performance of construction projects. Subsequently, enforcement as an introduced mediator has considerably mediated the negative effects of influence as compliance barriers on the cost performance of construction projects as an outcome variable.

2. Secondly, the hypothetical prediction was that, enforcement mediates the effects of project awards influencing on the cost performance of construction projects. This is perhaps due to the fear of the penalties and other persecution measures. It also might be because of the great supremacy of the enforcement being a strong compliance mechanism. The results contribute to the emerging research in mediation analysis, especially in that, the study used process macro, which is one of the latest statistical mediation tools in the current mediation research trends (Hayes, 2013[a]). In addition, the findings of the current research have provided empirical evidence that cost performance of construction projects is affected by the influencing of project awards in Nigerian federal universities. Furthermore, enforcement as the proposed mediator has shown the tendency of mediating the effects of the influences on the cost performance of construction projects. This is the main contribution of the study: thus, it serves as an added knowledge to the contribution of prior studies on issues related to compliance with public procurement guidelines. The study supported the findings of Tukamuhabwa (2012) that influencing project awards is one of the antecedents of public procurement non-compliance behaviour. In the same vein, the findings conform to the study of Ademola and Ajibola (2014) that influencing the project award's decision significantly contributes to non-compliance with procurement guidelines in the procurement of public works in Nigeria. Conversely, the result of this study contradicts the findings of Ombuki et al. (2014) that 95\% of the projects awarded in the public universities' procurement in Kenya are influenced by politicians alone. 
Table 8. Summary of the Process Macro Mediation Results for the Final Model of the Study

\begin{tabular}{lcccc}
\hline \multicolumn{1}{c}{ Variable Relationships } & Coeff & P-Value & $\begin{array}{c}95 \% \mathbf{~ L L C l} \text { and } \\
\mathbf{U L C l}\end{array}$ & Decision \\
\hline $\begin{array}{l}\text { Total effect of Inflc on CstPermf } \\
\text { (c-path) }\end{array}$ & 0.2841 & $0.0000^{*}$ & $\begin{array}{c}(0.2535, \\
0.3148)^{*}\end{array}$ & Significant \\
$\begin{array}{l}\text { Indirect effects of Inflc on } \\
\text { Enfrcment (a-path) }\end{array}$ & 0.4305 & $0.0000^{*}$ & $\begin{array}{c}(0.4113, \\
0.4496)^{*}\end{array}$ & Significant \\
$\begin{array}{l}\text { Indirect effects of Enfrcment on } \\
\text { CstPerf (b-path) }\end{array}$ & 1.1196 & $0.0000^{*}$ & $\begin{array}{l}(1.0026, \\
1.2366)^{*}\end{array}$ & Significant \\
$\begin{array}{l}\text { Direct effects of Inflc on CstPermf } \\
\text { through Enfrcment (C'-path) }\end{array}$ & -0.1978 & $0.0000^{* *}$ & $\begin{array}{c}(-0.2528 \text { and } \\
-0.1429)^{* *}\end{array}$ & Insignificant \\
\hline
\end{tabular}

Notes: *Significant at the 0.05 level of significance; ${ }^{* *}$ Insignificant at the 0.05 level of significance.

\section{CONCLUSSION AND RECOMMENDATIONS}

The study identified conflict of interest in construction procurement process as barriers to compliance with PPGs. The study also assessed the mediating effects of enforcement as an effective compliance tool between influencing projects' award and the cost performance of construction projects in Nigerian federal universities. Influencing project awards that affect compliance with public procurement guidelines were the internal influence of project awards within the procurement entities and external influences at the ministry and public organisations. These identified barriers to compliance with PPGs were observed with significant statistical relationships effects with the cost performance of construction projects in Nigeria. This means that, influencing project awards as the independent variables of the study were observed to be significantly affecting the performance of construction projects, cost-wise. It is equally observed that, contract sum of the projects awarded based on influences either within or outside the procurement entities tended to be irrationally high. This is because the contractor has to make provisions for kickback and some other lobbying incentives that might be prerequisite to the project award. In order to suggest a remedy for improvement, enforcement was identified and introduced as a mediator in the study model. The mediation analysis shows that the enforcement mechanism has mediated the large negative effects of the project award influencing on the cost performance of construction projects. The study, therefore, recommends that the necessary actions to ensure enforcement measures be put in place by the Bureau of Public Procurement (BPP), as the apex administrative body for ensuring compliance with the PPGs in Nigeria. A National Council of Public Procurement (NCPP) should also be established as highlighted by the PPA 2007. This would go a long way in tackling the unceasing influencing of project awards in Nigerian federal universities. The NCPP, when fully established, will be wholly responsible for the awarding of federal capital projects in Nigeria, including those to the federal universities which at the moment is a role being played by the National Executive Council (NEC). And, this has remained one of the causes of project award influencing, which contradicts the provision of the public procurement policies currently in use. When introducing the enforcement 
measures, the study recommends for strong penalties and constraining actions for any stakeholder or project party involved in project award influencing. It is over ten years now since the enactment of the PPA 2007 part of which the PPGs were highlighted. The federal government ought to take a bold step to ensure that enforcement measures are put in place in order to save ample public funds whilst delivering projects of high quality.

\section{IMPLICATION AND LIMITATION OF THE STUDY}

The practicality of the findings acknowledges enforcement as an effective compliance mechanism to improve the compliance with the PPGs and construction project cost performance. The construction industry should recognise the role of enforcing construction procurement regulations, especially the PPGs, towards enhancing project performance cost-wise that gives the client good value for money. The analysis enables public authorities to identify some of the reasons for the selective implementation of the PPGs and their negative implications on public procurement practices, especially for construction procurement practices within the procurement entities of Nigerian federal universities. Theoretically, the study conceptualises the influencing of project awards identified as barriers to compliance with the PPGs, affecting construction project cost performance in Nigerian federal universities. Thus, the study's major findings have resulted in the development of an enforcement-based mediation model that establishes a linkage between the PPGs compliance barriers (influencing projects award) and construction project cost performance, which has filled in the literature gap earlier. In terms of sample size, the study is limited only to the procurement entities of Nigerian federal universities. As such, future research should consider Nigerian federal polytechnics and other federal tertiary institutions deemed to apply PPGs. in relation to the study variables, the study covered only influencing project awards both at the procurement entity and ministry levels. As such, other barriers to compliance with the PPGs should be considered by future researchers.

\section{ACKNOWLEDGEMENTS}

This research work was supported by the Universiti Sains Malaysia (USM) Fellowship Scheme. The authors would like to fully acknowledge the financial support offered for undertaking the research.

\section{REFERENCES}

Abdullahi, N.Z., Hussin, A.A. and Osmadi, A. (2015). Determinants of compliance with public procurement guidelines in the Nigerian construction industry. Jurnal Teknologi, 75(9): 107-110.

Ademola, E.O. and Ajibola, M.G. (2014). An assessment of non-compliance with procurement proceedings in procurement of works in Nigeria. International Journal of Economic and Business Management, 2(3): 25-34. 
Akech, J. (2006). Development partners and governance of public procurement in Kenya: Enhancing democracy in the administration of aid. New York University Journal of International Law and Politics, 37(4): 829.

Akinsiku, O.E. and lyagba, O.A. (2014). Cost and time performance of construction projects: A comparative study of Southern Peninsular Malaysia and Lagos, Nigeria. Palgo Journal of Education Research, 2(2): 75-82.

Ameyaw, C., Mensah, S. and Osei-Tutu, E. (2011). Challenges facing the smooth implementation of Ghana's Public Procurement Law 2003, Act 663. Proceedings: West Africa Built Environment Research (WABER) Conference. Accra, Ghana, 19-21 July.

Azhar, N., Farooqui, R.U. and Ahmed, S.M. (2008). Cost overrun factors in construction industry of Pakistan. Paper presented at the First International Conference on Construction in Developing Countries (ICCIDC-I): Proceedings on Advancing and Integrating Construction Education, Research and Practice. Karachi, Pakistan, 4-5 August.

Baron, R.M. and Kenny, D.A. (1986). The moderator-mediator variable distinction in social psychological research: Conceptual, strategic and statistical considerations. Journal of Personality and Social Psychology, 51(6): 11731182. https://doi.org/10.1037/0022-3514.51.6.1173.

Bolton, P. and Dewatripont, M. (2005). Contract Theory. Cambridge, MA: MIT Press.

Cooke-Davies, T. (2002). The "real" success factors on projects. International Journal of Project Management, 20(3): 185-190. https://doi.org/10.1016/S02637863(01)00067-9.

Cornalba, C. and Giudici, P. (2004). Statistical models for operational risk management. Physica A: Statistical Mechanics and Its Applications, 338: 166-172. https://doi.org/10.1016/j.physa.2004.02.039.

Dahiru, A. (2014). Conflict of interests in public procurement management in Nigeria. Paper presented at the NIQS National Seminar on Procurement of Construction Works and Services: Adapting to Contemporary Challenges. Gombe, Nigeria, 11-12 June.

Dalenius, T. and Hodges Jr, J.L. (1959). Minimum variance stratification. Journal of the American Statistical Association, 54(285): 88-101. https://doi.org/10.1080/ 01621459.1959 .10501501$.

Dulaimi, M.F. and Shan, H.G. (2002). The factors influencing bid mark-up decisions of large-and medium-size contractors in Singapore. Construction Management and Economics, 20(7): 601-610. https://doi.org/10.1080/01446190210159890.

Eshofonie, F.P. (2008). Factors affecting Cost of Construction in Nigeria. Lagos, Nigeria: University of Lagos.

Eyaa, S. and Oluka, P.N. (2011). Explaining non-compliance in public procurement in Uganda. International Journal of Business and Social Science, 2(1 1): 35-44.

Fayomi, I.O. (2013). Public procurement and due process policy in Nigeria: Thrust, prospects and challenges. Peak Journal of Social Sciences and Humanities, $1(4): 39-45$.

Frimpong, Y., Oluwoye, J. and Crawford, L. (2003). Causes of delay and cost overruns in construction of groundwater projects in a developing countries: Ghana as a case study. International Journal of Project Management, 21 (5): 321-326. https://doi.org/10.1016/S0263-7863(02)00055-8. 
Gambo, N. and Said, I. (2014). A conceptual framework for improving cost and building contractor performances in developing countries. Paper presented at the 7th International Real Estate Research Symposium (IRERS) 2014. National Institute of Valuation (INSPEN), Selangor, Malaysia, 29-30 April.

Gambo, N., Said, I. and Ismail, R. (2016). Influences of cost factors affecting technical performance of local government projects in Nigeria: A partial least square-structural equation modeling (PLS-SEM) approach. Journal of Construction in Developing Countries, 21 (1): 85-1 11. https://doi.org/10.21315/ jcdc2016.21.1.5.

Gunningham, N. and Kagan, R.A. (2005). Regulation and business behavior. Law and Policy, 27(2): 213-218. https://doi.org/10.1111/j.1467-9930.2005.00197.x.

Hair, J.F., Black, W.C., Babin, B.J., Anderson, R.E. and Tatham, R.L. (2006). Multivariate Data Analysis. Upper Saddle River, NJ: Pearson Prentice Hall.

Hayes, A.F. (2013a). Introduction to Mediation, Moderation and Conditional Process Analysis: A Regression-Based Approach. New York: Guilford Press. . (2013b). Model Templates for PROCESS for SPSS and SAS [White Paper]. Available at: http://www.afhayes.com/ [Accessed on 7 March 2016].

. (2012). Process: A Versatile Computational Tool for Observed Variable Mediation, Moderation and Conditional Process Modeling [White Paper]. Available at: http://www.afhayes.com/public/process2012.pdf.

Hayes, A.F. and Preacher, K.J. (2014). Statistical mediation analysis with a multicategorical independent variable. British Journal of Mathematical and Statistical Psychology, 67(3): 451-470. https://doi.org/10.1111/bmsp.12028.

Hui, S.W., Radiah, O., Normah, H.O., Rashidah, A.R. and Nurul, H.H. (201 1). Procurement issues in Malaysia. International Journal of Public Sector Management, 24: 567-593. https://doi.org/10.1108/095135511111163666.

Imperato, G.L. (2005). Corporate crime, responsibility, compliance and governance. Journal of Health Care Compliance, 3(7): 11-19.

Jacob, O. (2010). Procurement law in Nigeria: Challenge for attainment of its objectives. University of Botswana Law Journal, 4(1): 131-151.

Jibrin, M.S., Ejura, S.B. and Augustine, N.I. (2014). The public procurement reforms in Nigeria: Implementation and compliance challenges. Journal of Asian Business Strategy, 4(11): 149-162.

Kangogo, J. and Kiptoo, E.J. (2013). Factors affecting ethical standards in public procurement in Kenya. International Journal of Management Science, 1(3): 90-99.

Koelmans, R. (2004). Project success and performance evaluation. International Platinum Conference: Platinum Adding Value. Johannesburg: South African Institute of Mining and Metallurgy.

Low, S.P. and Quek, T.C. (2006). Environmental factors and work performance of project managers in the construction industry. International Journal of Project Management, 24(1): 24-37. https://doi.org/10.1016/j.ijproman.2005.06.001.

Mackinnon, D.P., Lockwood, C.M. and Williams, J. (2004). Confidence limits for the indirect effect: Distribution of the product and resampling methods. Multivariate Behavioral Research, 39(1): 99-128. https://doi.org/10.1207/ s15327906mbr3901_4.

Migosi, J.A., Ombuki, C.N., Ombuki, K.N. and Evusa, Z. (2013). Determinants of noncompliance of public procurement regulations in Kenyan secondary schools. International Journal of Educational Administration and Policy Studies, 5: 154159. 
National Population Commission (2000). Nigeria Demographic and Health Survey 1999. Calverton, Maryland: National Population Commission and ORC/ Macro.

National Universities Commission (NUC) (2015). Procurement Entities of Federal Universities. Abuja, Nigeria: NUC.

Ng, S.T., Palaneeswaran, E. and Kumaraswamy, M.M. (2002). A dynamic e-Reporting system for contractor's performance appraisal. Advances in Engineering Software, 33(6): 339-349. https://doi.org/10.1016/S0965-9978(02)00042-X.

Ojo, E. and Gbadebo, A. (2014). An assessment of non-compliance with procurement proceedings in procurement of works in Nigeria. International Journal of Economic and Business Management, 2(3): 25-34.

Okeahalam, C.C. (2004). Corporate governance and disclosure in Africa: Issues and challenges. Journal of Financial Regulation and Compliance, 12(4): 359-370.

Onchweri, N.N. and Muturi, W. (2015). Determinants of compliance in public procurement regulations in the public sector: A case study of Kisii Country. Kenya International Journal of Economics, Commerce and Management, 3(10): 749-758.

Onyinkwa, J. (2013). Factors influencing compliance to procurement regulations in public secondary schools in Kenya: A case of Nyamache District, Kisll County. Interdisciplinary Journal of Contemporary Research in Business, 5(1): 561-592.

Othman, R., Zakaria, H., Nordin, N., Shahidan, Z. and Jusoff, K. (2010). The Malaysian public procurement's prevalent system and its weaknesses. American Journal of Economics and Business Administration, 2(1): 6. https://doi.org/10.3844/ ajebasp.2010.6.11.

Oyeyipo, O.O., Odusami, K.T., Ojebi, R.A. and Afolabi, A.O. (2016). Factors affecting contractors' bidding decision for construction projects in Nigeria. Journal of Construction in Developing Countries, 21 (2): 21-35. https://doi.org/10.21315/ jcdc2016.21.2.2.

Pallant, J. (201 1). SPSS Survival Manual: A Step by Step Guide to Data Analysis Using SPSS Version 18. 4th Ed. Berkshire: Open University Press.

Pillay, S. (2004). Corruption: The challenge to good governance; A South African perspective. International Journal of Public Sector Management, 17(7): 586605. https://doi.org/10.1108/09513550410562266.

Raymond, J. (2008). Benchmarking in public procurement. Benchmarking: An International Journal, 15(6): 782-793.

Reimarová, H. (201 1). Transaction costs in public procurement. Diploma diss. Charles University in Prague.

Sang, W.K. and Mugambi, F. (2014). Factors affecting compliance with public procurement laws and regulations in public institutions in Kenya: A case study of public entities in Mombasa County. International Journal of Social Sciences and Entrepreneurship, 1(11): 650-671.

Scott, W.R. (2005). Institutional theory: Contributing to a theoretical research program. In K.G. Smith and M.A. Hitt (eds.). Great Minds in Management: The Process of Theory Development. New York: Oxford University Press, 460-484.

Sekaran, U. and Bougie, R. (2011). Research Method for Business: A Skill Building Approach. Abingdon: Taylor and Francis.

Shehu, A.S. (2014). An overview of public procurement guidelines in Nigeria. Proceeding on the Procurement of Construction Works and Services: Adapting to Contemporary Challenges. Gombe International Hotel, Nigeria, 11-12 June. 
Sobel, M.E. (1986). Some new results on indirect effects and their standard errors in covariance structure models. Sociological Methodology, 16: 159-186.

Sutinen, J.G. and Kuperan, K. (1999). A socio-economic theory of regulatory compliance. International Journal of Social Economics, 26(1/2/3): 174-193.

Tukamuhabwa, B.R. (2012). Antecedents and consequences of public procurement non-compliance behavior. Journal of Economics and Behavioral Studies, 4(1): 34-46.

Williams-Elegbe, S. (2009). A comparative analysis of the Nigerian Public Procurement Act against international best practice. Journal of African Law, 50(1): 85-98.

Williams-Elegbe, S. (2011). The reform and regulation of public procurement in Nigeria. Public Contract Law Journal, 41 (2): 339-366.

Zubcic, J. and Sims, R. (2011). Examining the link between enforcement activity and corporate compliance by Australian companies and the implications for regulators. International Journal of Law and Management, 53(4): 299-308. https://doi.org/10.1108/175424311111147800.

Zyl, D.C.V. (2006). Strategic supply chain management by Matatiele Municipality. $\mathrm{PhD}$ diss. University of Stellenbosch. 